\title{
Vieilles souris
}

\section{Erhard Taverna}

Dr méd., membre de la rédaction

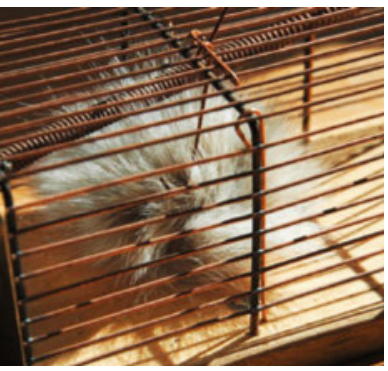

La première épopée de l'histoire de l'humanité parle de la quête de l'immortalité. Gilgamesh trouve la plante légendaire, mais un serpent l'en prive en l'avalant. Après lui, Hippocrate devient le père de la médecine antivieillissement. Ses conseils de diététique lui auraient permis de vivre plus de 100 ans. Goethe buvait jusqu'à deux bouteilles de vin par jour; plus tard, d'autres s'injectaient des testicules de chien ou cherchaient la jeunesse éternelle dans le lait caillé. Le chirurgien Voronoff greffait des testicules de singe à ses patients dans les années 1920 et Paul Niehans (1882-1971) a mis au point la thérapie à base de cellules fraîches. Dans son institut de Montreux, il a réalisé des injections de cellules tirées d'organes de fotus de mouton et d'agneaux nouveau-nés. Selon Swiss Health, la plateforme de commercialisation du tourisme médical en Suisse, jusqu'à 10000 Chinois se font revitaliser chaque année au bord du lac Léman (2014). Aux Etats-Unis, les adeptes du mouvement Radical Life Extension promeuvent une espérance de vie de mille ans.

Toutes ces expériences ont en commun la consommation d'un soi-disant élixir, chaque méthode reflétant le savoir de son temps. Une publication du prestigieux magazine scientifique Nature d'avril 2017 devrait avoir donné des ailes à de nombreux chercheurs du secteur anti-âge. Human umbilical cord plasma proteins revitalize hippocampal function in aged mice: telle était la bonne nouvelle. Une protéine du nom de TIMP-2 présente dans le sang de cordon ombilical redonne la pêche à des souris âgées. Des expériences antérieures auraient déjà montré qu'un «branchement» direct sur un circuit jeune rajeunit tous les organes. L'événement a été célébré par les médias comme le big bang d'un cheminement vers l'allongement de la vie. Certaines cliniques privées des Etats-Unis proposent déjà des transfusions de sang frais de jeunes donneurs à des vieillards fortunés. Et si le fantasme devenait réalité et que Novartis finissait par commercialiser une méthode rajeunissante? Elle serait sans doute hors de prix. Autrement dit, bienvenue dans le monde des riches, des cent-cinquantenaires en pleine forme, qui grâce à leur supériorité technologique tiennent les masses pauvres en échec depuis leurs îlots de prospérité. Toutes les rêveries de ce type aboutissent à des dystopies. Le sang, fluide vital, est un thème cher à la littérature pop et au cinéma. Les suceurs de sang, comme notre bien-aimé Dracula, sont présents dans toutes les cultures. Respectivement en Chine et au Japon, le jiangshi ou kyonchi se nourrit du chi, c.-à-d. de l'énergie de ses victimes. L'Afrique connaît des centaines de démons, parmi lesquels l'adze, dont la boisson de prédilection, outre l'huile de palme et le lait de coco, est le sang des enfants. Rien qu'au cours de ce siècle, plus de 200 films déclinent de manière obsessionnelle le thème des suceurs de sang ou des zombies carnivores. Qui ne connaît pas ces morts-vivants qui passent leurs journées dans un cercueil et mordent le cou de belles jeunes femmes la nuit? Encore plus sinistres: les hordes chancelantes qui quittent les cimetières pour chasser les vivants. Les films d'horreur sont les supports idéaux pour projeter toutes sortes de peurs: du sida, des épidémies ou du désir d'immortalité. Les vampires et les zombies prolongent leur existence aux dépens des vivants. Même si on les combat par tous les moyens, leur rage de vivre et leur puissance quasi indestructible fascinent. Ils sont le mal infini dans un monde manichéen, le pendant de la Cène, où le pain et le vin sont la clé de la résurrection et de la vie éternelle. La culture pop intègre toujours une parcelle de vérité, un reflet des intentions de la science. La recherche sur les mouches du vinaigre et les souris de laboratoire, les expériences sur les gènes et les cellulessouches ont quelque chose d'ambivalent. Elles doivent guérir les maladies, rien de plus. Mais elles vont évidemment bien plus loin lorsqu'il s'agit d'améliorer les capacités humaines ou de prolonger la vie de personnes en bonne santé. La frontière entre l'espoir et la peur est ténue. Les immortels ont mauvaise presse dans la littérature. Une malédiction poursuit le Juif errant et le Hollandais volant perdus et solitaires au long des siècles. D'autres qui ont indûment prolongé leur vie s'abrutissent ou régressent jusqu'à devenir des créatures simiesques qu'il faut enfermer. Les contes et les mythes rappellent que l'enjeu ne se limite pas à la conservation de nos organes. Les sirènes qui s'éprennent d'un être humain sacrifient leur immortalité en échange d'une âme. Dans ces représentations, l'être humain possède quelque chose que n'ont pas les esprits élémentaires, quelque chose d'immatériel qui lie son corps affaibli par l'âge à un monde supérieur.

Dans sa cage de laboratoire, la souris recevra peut-être d'autres injections et continuera de rajeunir. Elle pourra manger et copuler pour l'éternité, mais elle restera à jamais derrière ses barreaux. 